\title{
How does a photocatalytic antimicrobial coating affect environmental bioburden in hospitals?
}

M. Reid MSc; ${ }^{1}$ V. Whatley BSc; ${ }^{1}$ E. Spooner BSc; ${ }^{1}$ A.M. Nevill PhD; ${ }^{2}$ M. Cooper FRCPath; ${ }^{1}$ J.J. Ramsden DSc, FIMMM; ${ }^{3}$ S.J. Dancer MD, FRCPath ${ }^{4,5}$

\footnotetext{
${ }^{1}$ New Cross Hospital, The Royal Wolverhampton NHS Trust, England

${ }^{2}$ Faculty of Education, Health and Wellbeing, University of Wolverhampton, England

${ }^{3}$ Clore Laboratory, University of Buckingham, England

${ }^{4}$ Department of Microbiology, Hairmyres Hospital, NHS Lanarkshire, Scotland

${ }^{5}$ School of Applied Sciences, Edinburgh Napier University, Edinburgh, Scotland
}

\section{CORRESPONDING AUTHOR}

Prof. J.J. Ramsden, University of Buckingham, MK18 1EG, UK. Telephone: +44 1525 302439; fax: +44 1525 841220; e-mail: jeremy.ramsden@buckingham.ac.uk

\section{SHORT TITLE}

Evaluation of a photocatalytic coating on hospital surfaces

Word count for text body (i.e., excluding this page, abstract, acknowledgments, references and figure legend): 2,962 


\section{Background:}

The healthcare environment is recognized as a source for healthcare-acquired infection. Since cleaning practices are often erratic and always intermittent, it is postulated that continuously antimicrobial surfaces offer superior control of surface bioburden.

\section{Objective:}

This study evaluated the impact of a photocatalytic antimicrobial coating at near-patient high-touch sites in a hospital ward.

\section{Setting:}

Two acute wards in a large acute hospital.

\section{Methods:}

A titanium dioxide-based photocatalytic coating was sprayed onto six surfaces within a four-bed bay in a ward and compared against the same surfaces in an untreated ward, both under normal illumination. Sites were right and left bedrails; bed control; bedside locker, overbed table; and bed footboard. Overall microbial burden and presence of an indicator pathogen (S. aureus) were assessed biweekly using standardized methods for 12 weeks.

\section{Results:}

Treated surfaces demonstrated significantly lower microbial burden than control sites, with the difference increasing between treated and untreated surfaces during the study. Hygiene failures $\left(>2.5 \mathrm{cfu} / \mathrm{cm}^{2}\right)$ increased $2.6 \%$ per day $(\mathrm{OR}=1.026 ; 95 \% \mathrm{Cl} 1.009$ to $1.043 ; P=0.003)$ for control surfaces but declined $2.5 \%$ per day for treated surfaces (OR=0.95; $95 \% \mathrm{Cl} 0.925$ to $0.977 ; P<$ 0.001).There was no significant difference between coated and control surfaces regarding S. aureus contamination.

\section{Conclusion:}

Photocatalytic coatings reduced the bioburden of high-risk surfaces in the healthcare environment: treated surfaces became steadily cleaner, while untreated ones accumulated bioburden. This evaluation encourages a larger-scale investigation to ascertain whether the observed environmental amelioration has an effect on healthcare-acquired infection. 


\section{Introduction}

Increasing microbial antibiotic resistance has given new impetus to keeping hospitals clean. ${ }^{1}$ Hospital-acquired infection (HAl) is rightly seen as an unacceptable burden on the patient, as well as inflating hospital costs. ${ }^{1}$ While there is general agreement on the need to control $\mathrm{HAl}$, there is diversity of opinion regarding the best solution. A major problem is the difficulty of conclusively establishing a causal link between surface contamination and $\mathrm{HAl}^{2}$, compounded by the lack of universally accepted standards for measuring cleanliness. ${ }^{3}$ Nevertheless, it is plausible to assert that there is such a link ${ }^{4}$, allowing us to debate the most cost-effective method for reducing contamination in the healthcare environment.

Current decontamination strategies include daily detergent- and disinfectant-based cleaning. Enhanced disinfection methods are available for rooms housing HAl patients and when an outbreak occurs. ${ }^{5}$ Powerful disinfectants require caution, since few have been properly evaluated under actual conditions of use, and they may ultimately be no better than traditional detergent-based cleaning. ${ }^{6,7}$ Manual cleaning has deficits, usually attributed to personnel rather than product, and recontamination inevitably begins immediately after the cleaning. ${ }^{8,9}$

Among recent technologies are photocatalytic antimicrobial coatings. ${ }^{10}$ They kill microbes by generating powerful oxidizing radicals on a semiconductor surface following light absorption in the presence of $\mathrm{O}_{2}$ and $\mathrm{H}_{2} \mathrm{O}$. The most important photocatalytic material is titanium dioxide (titania) because the bandgap of the semiconductor overlaps sufficiently with the spectrum of natural and common artificial light sources; the band edges are positioned appropriately for generating the radicals; and the material is stable with respect 
to self-destruction. ${ }^{10,11}$ The illuminated semiconductor acts as a source of reactive oxygen species (ROS), which are known to be highly effective microbicides ${ }^{12}$; the mechanism of antimicrobial destruction is believed to involve bacterial cell-wall damage. ${ }^{13}$ Those ROS generated by illuminated titania are particularly reactive and it is thought that resistance against them cannot be developed. ${ }^{12}$

Although there have been in vitro investigations of photocatalytic antimicrobial action with titania, very little work in real-life situations has been reported. ${ }^{10} \mathrm{~A}$ commercial titania coating ("EnviroCare") did not significantly prevent environmental microbial contamination. ${ }^{14}$ This coating was, however, constituted from titania particles dispersed in a binder in order to ensure their attachment to the coated surfaces; the binder possibly encapsulated the particles and not only scavenged the photogenerated radicals but also formed a physical barrier between the particles and the microbes. Titania nanoparticles in suspension have been shown to be effective photocatalytic antimicrobial agents but they adhere very weakly to most surfaces ${ }^{10,15}$, from which they would, therefore, be continuously lost. Petti and Messano dispersed titania nanoparticles in PVC and observed antimicrobial action on the surface of blocks made from the polymer ${ }^{16}$, but this approach is obviously unsuitable for retrofitting to existing objects.

We resolved to evaluate a material (MVX) that is applied as a dilute aqueous sol of titania nanoparticles, which dries and gels to form a tough, adherent monolithic film on the coated surface. Given evidence that photocatalytic antimicrobial activity can be synergistically enhanced by the presence of copper or silver ${ }^{11}$, we chose to use a product doped with a small proportion of silver zeolite. While it was tempting to coat all surfaces in a ward due to ease of application (by spraying), we focused on near-patient high-touch surfaces. They 
were coated immediately after annual deep clean of the wards. Following the application, the microbial burden and associated pathogens were monitored over three months using standardized methods.

\section{Setting}

The coated bay was in an acute general medical ward, and an untreated control bay was selected in the stroke unit. The decision to spatially separate the treated and control bays, rather than having them in the same ward, was taken to avoid introducing a confounding factor in the form of a possible effect of the coating on resident staff hands, who potentially have access to all patients on the same ward. Both wards are located in a part of the hospital constructed in 2004, and are architecturally almost identical. The bays have a rectangular shape and a volume of approximately $144 \mathrm{~m}^{3}$. They are naturally ventilated with windows along one of the long sides facing north; artificial light is provided during waking hours (dimmed during the hours of sleep) from "daylight" fluorescent lamps. At patient level the illuminance was approximately 400lux.

\section{Methods}

\section{Choice of surface sites for coating}

It was decided to coat (i) left- and (ii) right-hand side rails of a standard hospital bed; (iii) the front face of the bed control panel; (iv) the top of the bedside table ( $v$ ) the bedside locker (in entirety, but only the top was sampled); and (vi) the bed footboard (only the top was sampled). There is general consensus about the potential HAl risk from these sites. ${ }^{17}$ The furniture (table and locker) was made from laminated wood. Each of these six sites was replicated for all four bedspaces occupying one bay of the selected ward. 


\section{Ward preparation}

Prior to coating the wards were deep-cleaned, which comprises thorough cleaning with a $5000 \mathrm{ppm}$ solution of Actichlor Plus (Ecolab, UK) (a combination of a chlorine-compatible detergent with sodium dichloroisocyanurate, NaDCC, also known as troclosene sodium) followed by steam cleaning and, as a final step, enhanced cleaning with hydrogen peroxide vapour (HPV, Deprox; Specialist Hygiene Solutions Ltd, Kings Lynn, UK). The stroke ward was deep-cleaned in the week commencing 1 August 2016 and the acute medical ward was deep-cleaned in the week commencing 10 September. No patients were admitted to the ward between deep cleaning and coating.

\section{Coating procedure}

The coating is a dual one, comprising a colourless primer ("Primary") over which the photocatalytic titania coating ("MVX") is laid. Final coating thickness was approximately $1 \mu \mathrm{m}$. The precursors are dilute aqueous solutions of the active ingredients, titania (1.5\%) and silver zeolite $(0.1 \%) .{ }^{18}$ These solutions, as well as the final coating, are nontoxic to humans. ${ }^{21}$ Primary (MVX Hitech Co. Ltd, Kitakyushu, Japan) was sprayed onto the selected surfaces and allowed to dry for 20-30min; the ambient temperature in the ward during coating was $26 \pm 1^{\circ} \mathrm{C}$ and the relative humidity was $59 \pm 3 \%$. Then MVX was applied likewise by spraying and similarly allowed to dry. After drying, the coating was invisible to the eye, even on mirrors (integral on some lockers). All coated objects were discreetly fitted with trackers for the TeleTracking Technologies (Pittsburgh, Pennsylvania) real-time location system (RTLS) installed at the hospital as part of the "Safe Hands" programme, to ensure that the coated objects could always be unambiguously located, even if clinical exigence (e.g., to 
reduce the risk of falls, or simply to make the patient more visible) led to a patient (with bed and bedspace equipment/furniture) being moved, generally within the ward.

\section{Sampling protocol}

The approach followed that described in Bogusz et al. ${ }^{19}$ Starting at 7am on Tuesdays and Thursdays, for 12 weeks (22 September-21 December 2016), after locating the objects with the RTLS, the coated sites and their uncoated equivalents were sampled using double-sided dipslides (Hygiena International, Watford, UK) coated with nutrient and Baird Parker agars, pressing the slides at $25 \mathrm{~g} / \mathrm{cm}^{2}$ for $5 \mathrm{~s} .{ }^{20}$ Within the sites, the actual locations were determined at random ${ }^{21}$, according to the judgment of the (sole) sampler.

\section{Microbiology}

Dipslides were incubated for $48-72 \mathrm{~h}$ at $36 \pm 1^{\circ} \mathrm{C}$ according to laboratory protocol, after which the number of aerobic colony-forming units (cfu) was determined from the nutrient agar side. Baird Parker agar highlighted potential coagulase-positive staphylococci, which were subcultured onto blood agar and identified as methicillin-susceptible or -resistant according to laboratory protocol. The aerobic colony count (ACC) was quantified using a 5-point scale (Table 1). ${ }^{3,7,19}$ Staphylococci were classified as either "isolated" or "not isolated".

\section{Ward environment}

Every day, the ward cleaning team cleaned all items in the patient bed space with Hospec general surface cleaner (containing alcohol ethoxylate as the detergent) (Robert McBride Ltd, UK), typically during the morning after sampling. No exceptional cleaning (HPV or Actichlor Plus) was requested for the control ward during the study. Actichlor Plus was 
requested on three occasions in the treated ward, but for side rooms away from the treated bay. Unlike the strongly bactericidal ionic surfactants, nonionic surfactants are generally considered to be less bactericidal, although they interfere with bacterial membrane fluidity. ${ }^{22}$ It is difficult to separate the physical bactericidal effect of the mechanical wiping action from the biochemical bactericidal effect associated with the surfactant ${ }^{23}$, but some attempts at quantification have been made.,19

Bed occupancy was high in both treated and control wards, averaging $97.6 \%$ for the former and $88.0 \%$ for the latter during the study (data for the entire ward). Locally agreed staffing levels are recorded for all wards at the hospital. The stroke ward was generally better staffed than the acute ward. Medical staff, allied health professionals (AHP, including physiotherapists, occupational therapists, speech and language therapists) and domestics were not included, nor were visitor numbers monitored.

The degree of dependency (acuity) of the patients occupying the beds was also examined. The median degree was invariably level $1 \mathrm{~b}$ using the Hurst classification. ${ }^{24}$

The hospital R\&D department determined not to class the study as research but rather as a service evaluation. Therefore, Research Ethics Committee approval was not required.

\section{Statistical methods}

The sampling protocol resulted in a maximum of 102 bedspace observations for each ward subsequently available for statistical analysis. Each observation produced six measurements of ACCs, which were allocated a numerical descriptor from 1 to 5 (Table 1). For the statistical analysis, a mean "numerical descriptor" score (i.e., arithmetic mean of the six test sites) was calculated for each bedspace. This was dichotomized into a pass/fail outcome 
variable (1-2 = "pass" and $>2-5=$ "fail"). Although dichotomizing may lead to a loss of statistical power, ${ }^{25}$ it is in concordance with the previously introduced pass/fail dichotomy for bioburden. ${ }^{3,26}$ Furthermore, the conventional classification (Table 1) gives a highly nonlinear mapping of ACCs onto a descriptor; by dichotomizing we avoid having to discuss whether to express the results in terms of $\mathrm{cfu} / \mathrm{cm}^{2}$ or in terms of the "degree of growth" descriptor.

The difference in pass/fail rate between the two wards (experimental and control) was assessed using the $\chi^{2}$ independence test. Straightforward binary logistic regression analysis was used to further explore the probability (odds) of failing the pass/fail test on the two wards. ${ }^{27}$ Additional factors (introduced as continuous covariates) included the number of days into the study (0-90) and the bed occupancy rate (\%) for each ward. The multiple regression logit model was fitted using the binary logistic regression analysis option in SPSS (SPSS Inc., Chicago, Illinois). The analysis allows both fixed and categorical factors and continuous covariates to be used as explanatory variables when estimating the probability (or, more correctly, the odds) of failing the test. $P<0.05$ was used as a measure of significance.

\section{Results}

The overall pass rate for the coated bay was $80.4 \%$ ( 82 passes out of a total of 102 samples), while for the control bay it was $52.9 \%$ (54 passes out of 102 ).

The results of the binary logistic regression analysis, using the control ward as the reference condition, are given in Table 2. The analysis identified no difference in the odds of failing the test between the two wards at the beginning of the experiment (odds ratio $O R=0.993$; 
$95 \% \mathrm{Cl} 0.267$ to $3.69 ; P=0.993)$. However, the odds of failing the test in the control bay increased by $2.6 \%$ per day $(B=0.026),(\mathrm{OR}=1.026 ; 95 \% \mathrm{Cl} 1.009$ to $1.043 ; P=0.003)$ but declined by $2.5 \%$ per day in the treated bay $(B=0.026-0.051),(\mathrm{OR}=0.95 ; 95 \% \mathrm{Cl} 0.925$ to 0.977; $P<0.001)$. These trends are plotted in Figure 1.

For the individual sites, we considered the sampling as a sequence of independent Bernoulli trials with the binary outcome of "pass" or "fail" and an initially unknown probability $p$ of passing, which was found from the maximum of the likelihood of $p$, given the observed sequence. ${ }^{28}$ The results are given in Table 3. MVX significantly improved microbial cleanliness at every site, although only borderline significance was achieved for the bed footboard. The left-hand and right-hand bedrails were conceived as internal controls for each other, but yielded different "pass" probabilities; there may have been physical differences in accessing the bedrails, such as one bedrail being closer to a wall or some other obstruction.

S. aureus was isolated from only about $10 \%$ of the dipslides: There were 97 isolates recovered from a total of 635 for the treated surfaces (all sites together), compared with 68 isolates from a total of 655 for the control surfaces. The low S. aureus counts render the difference insignificant.

\section{Discussion}

The gradual diminution of bioburden on the treated surfaces occurred although bed occupancy was higher than in the untreated bay, which would have likely encouraged heavier microbial contamination on ward surfaces. ${ }^{26}$ This result implies that gradual removal 
of the coating by mechanical abrasion from touching or cleaning, initially considered as a possibility, did not occur.

Among the possible confounding factors considered (Hawthorne effect; bed occupancy; staffing levels; and degree of patient dependency) only bed occupancy differed markedly between the treated and control bays. Although the patients differed between the two study bays, there was no evidence for a clinically significant difference with respect to the likelihood of individual patients and attendant staff contributing to the microbial burden in their environment.

Environmental audits undertaken to appraise housekeeping compliance with cleaning are reported in Table 4 for the interval of the study. They show little difference between the two wards.

It is interesting to compare the bioburden reduction provided by the photocatalytic coating with conventional detergent or disinfectant application to high-touch surfaces (UK hospitals, generally use detergents, and hospitals in the USA generally use disinfectants). Microbial counts from a wide range of hand-touch sites cleaned with detergent ranged from 2.5 to $40 \mathrm{cfu} / \mathrm{cm}^{22}$; detergent cleaning was shown to reduce bioburden from a preclean level of $6.7 \mathrm{cfu} / \mathrm{cm}^{2}$ to $3.5 .{ }^{19}$ On the other hand, disinfectant reduced median counts for high-touch sites to $0.1-0.6 \mathrm{cfu} / \mathrm{cm}^{2}{ }^{30} \mathrm{~A}$ major difficulty is that sampling methods, surfaces, sites (nearpatient hand-touch sites host different amounts and types of bioburden than floors or bathroom sites), cleaning agent exposure, and culture techniques are not standardized across studies. Another confounding factor is sampling methodology: greater quantities of 
bioburden are recovered from moistened swabs placed in broth then agar methods such as RODAC plates or dipslides.

Our results suggest that the chosen wards were already rather clean, especially with respect to $S$. aureus; the effect of the photocatalytic coating in lowering bioburden might be more prominent in a less stringently clean hospital. Conversely, a recent study of the effect of MVX in the critical care environment, which is always afforded priority for cleaning (e.g., routinely cleaned with alcohol thrice daily) found no significant microbiological benefit, despite in vitro data from the same coating showing pathogen inactivation. ${ }^{31}$ The duration of the study was only 4 weeks, however, which may anyway be inadequate to provide sufficient statistical power to show any significant difference between treatment and control.

Although a photocatalytic surface continuously maintains its antimicrobial action, the action is fairly slow. Kinetic laboratory studies, in which surfaces were deliberately contaminated with known amounts of bacteria, suggest that about one hour is needed to destroy half the bacteria. ${ }^{32,33}$ Hence, if a site had been adventitiously heavily contaminated a few minutes prior to sampling, the result would indicate a high bioburden, whereas sampling two hours later might indicate low contamination.

The ultimate objective for hospitals regarding cleanliness is to reduce the incidence of HAI. At present the relationship between microbial burden on hospital surfaces and the incidence of HAI remains unclear; no extant model allows one to predict the change in HAI incidence as a result of lowering environmental bioburden by a defined amount, and so far no empirical study appears to have tackled this deficit. A few studies have examined the link 
between standardized measurements of bioburden and HAI rates, but with inconclusive outcomes. ${ }^{2}$ Much attention has been given to the proposition that hands are the main vectors for transmission and, therefore, that frequent hand hygiene is the key to reducing $\mathrm{HAl}$, although the limitations of this approach were noted decades ago. ${ }^{34}$ Furthermore, although hand hygiene is strongly promoted in the healthcare setting, compliance is still far from what is considered to be ideal but may nevertheless have already reached a practical limit. ${ }^{35}$ In any case, hand contamination is most likely to be transmitted via the intermediary of high-touch surfaces, such as those investigated in the present study, rather than directly to another hand.

"Routine cleaning and disinfection is apparently not sufficient". ${ }^{36}$ Detailed investigation of routine processes may reveal weaknesses, in addition to those already discussed, alongside their irreducible intermittency. ${ }^{9,37}$ In contrast, a photocatalytic surface is continuously active. Some of the physicochemical changes induced in titania by light persist for many hours or days in the dark, reinforcing this continuity. ${ }^{38} \mathrm{~A}$ photocatalytic coating of the type evaluated here offers a new perspective for overcoming some of the present limitations in cleaning, disinfection, and hand hygiene. A further advantage is that the mechanism whereby photocatalytic antimicrobial coatings inactivate microbes is unlikely to lead to the development of resistance, ${ }^{12}$ the increase of which is of grave concern to public health authorities.

In conclusion, coating high-touch surfaces with a titania-based photocatalytic material significantly lowered bioburden compared with a control bay. The trend of continuously diminishing bioburden in the treated bay is encouraging, not least in comparison with the untreated control bay, in which the bioburden appeared to continuously increase. A much 
larger and longer study should now be undertaken with sufficient power to observe whether coating high-touch surfaces with an antimicrobial coating reduces the incidence of HAI. Although there is no evidence that non-touch surfaces (walls, ceilings, etc.) are reservoirs for microbes, empirically verifying or otherwise the proposition that coating all surfaces with a photocatalytic material reduces the incidence of HAl will be a further useful addition to knowledge.

\section{Acknowledgments}

We thank Lee Turner for having undertaken the dipslide sampling throughout the study. We thank Sue Lovegrove of the Microbiology Laboratory, New Cross Hospital for processing the dipslides. We thank Dr Khaled Hussein, MVX Hi-tech Co. Ltd (Kitakyushu, Japan) for valuable discussions about the photocatalytic coating and its properties, and MVX Hi-tech Co. Ltd for having provided the photocatalytic materials and the staff to spray them onto the chosen surfaces.

Financial support. The Collegium Basilea (Institute of Advanced Study) partly funded this work.

Potential conflicts of interest. All authors report no conflicts of interest relevant to this article. All authors submitted the ICMJE Form for Disclosure of Potential Conflicts of Interest. 


\section{References}

[1] Plowman R, Graves N, Griffin MA, et al. The rate and cost of hospital-acquired infections occurring in patients admitted to selected specialties of a district general hospital in England and the national burden imposed. J Hosp Infect 2001; 47: 198-209.

[2] Dancer SJ. Controlling hospital-acquired infection: focus on the role of the environment and new technologies for decontamination. Clin Microbiol Rev 2014; 27: 665-689.

[3] Dancer SJ. How do we assess hospital cleaning? A proposal for microbiological standards for surface hygiene in hospitals. J Hosp Infect 2004; 56: 10-15.

[4] Dancer SJ. Importance of the environment in methicillin-resistant Staphylococcus aureus (MRSA) acquisition: the case for hospital cleaning. Lancet Infect Dis 2008; 8: 101-113.

[5] Donskey CJ. Does improving surface cleaning and disinfection reduce healthcareassociated infections? Am J Infection Control 2013; 41: S12-S19.

[6] Dancer SJ. Dos and don'ts for hospital cleaning. Curr Opin Infect Dis 2016; 29: 415-423.

[7] Stewart M, Bogusz A, Hunter J, et al. Microbiological effect of cleaning near-patient sites with electrolysed water. Infect Control Hosp Epidemiol 2014; 35: 1505-1510.

[8] Hota B, Blom DW, Lyle EA, Weinstein RA, Hayden MK. Interventional evaluation of environmental contamination by vancomycin-resistant enterococci: failure of personnel, product, or procedure? J Hosp Infect 2009; 71: 123-131.

[9] Boyce JM, Havill NL, Lipka A, Havill H, Rizani R. Variations in hospital daily cleaning practices. Infect Control Hosp Epidemiol 2010; 31: 99-101. 
[10] Ramsden, JJ. Photocatalytic antimicrobial coatings. Nanotechnol Perceptions 2015; 11: 146-168.

[11] Hashimoto K, Irie $\mathrm{H}$, Fujishima A. $\mathrm{TiO}_{2}$ photocatalysis: a historical overview and future prospects. Jap J Appl Phys 2005; 44:8269-8285.

[12] Ramsden JJ. Can bacteria develop resistance to photocatalytically generated reactive oxygen species? J Biol Phys Chem 2017; 17: 47-51.

[13] Pulgarin C, Kiwi J, Nadtochenko V. Mechanism of photocatalytic bacterial in activation on TiO2 films involving cell-wall damage and lysis. Appl Catal B 2012; 128: 179-183.

[14] Leng CW, Soe TA, Wui LW, et al. Efficacy of titanium dioxide components in preventing environmental contamination by meticillin resistant Staphylococcus aureus (MRSA). Int/ J Infection Control 2013; 9: 1-8.

[15] Wolfrum EJ, Huang J, Blake DM, et al. Photocatalytic oxidation of bacteria, bacterial and fungal spores, and model biofilm components to carbon dioxide on titanium dioxide-coated surfaces. Environ Sci Technol 2002; 36: 3412-3419.

[16] Petti S, Messano GA. Nano-TiO2-based photocatalytic disinfection of environmental surfaces contaminated by methicillin-resistant Staphylococcus aureus. J Hosp Infect 2016; 93: $78-82$.

[17] Huslage K, Rutala WA, Sickbert-Bennett E, Weber DJ. A quantitative approach to defining "high-touch" surfaces in hospitals. Infect Control Hosp Epidemiol 2010; 31: 850-853.

[18] Primary and MVX technical specification 2016. Kitakyushu: Maeda-Kougyou, Co. Ltd. 
[19] Bogusz A, Stewart M, Hunter J, et al. How quickly do hospital surfaces become contaminated after detergent cleaning? Healthcare Infection 2013; 18: 3-9.

[20] Lewis T, Griffith C, Gallo M, Weinbren M. A modified benchmark for evaluating the cleaning of some hospital environmental surfaces. J Hosp Infect 2008; 69: 156-163.

[21] Ramsden JJ. Bioinformatics: An Introduction, ch. 6. London: Springer; 2015.

[22] Glover RE, Smith RR, Jones MV, Jackson SK, Rowlands CC. And EPR investigation of surfactant action on bacterial membranes. FEMS Microbiol Lett 1999; 177: 57-62.

[23] Dancer SJ. Missing a trick? Response to: 'disinfectant wipes are appropriate to control microbial bioburden from surfaces'. J Hosp Infect 2016; 92: 208-209.

[24] Hurst K, Smith A, Casey A, Fenton K, Scholefield H, Smith S. Calculating staffing requirements. Nursing Management 2008; 15: 26-34.

[25] Altman DG, Royston P. The cost of dichotomizing continuous variables. BMJ 2006; 332: 1080.

[26] Dancer SJ, White L, Robertson C. Monitoring environmental cleanliness on two surgical wards. Int J Environ Health Res 2008; 18: 357-364.

[27] Bagley SC, White H, Golomb BA. Logistic regression in the medical literature: Standards for use and reporting, with particular attention to one medical domain. J Clin Epidemiol 2001; 54: 979-985.

[28] Edwards AWF. Likelihood. Cambridge: University Press; 1972. 
[29] Griffith CJ, Cooper RA, Gilmore J, Davies C, Lewis M. An evaluation of hospital cleaning regimes and standards. J Hosp Infect 2000; 45: 19-28.

[30] Boyce JM, Havill NL, Havill HL, Mangione E, Dumigan DG, Moore BA. Comparison of fluorescent marker systems with 2 quantitative methods of assessing terminal cleaning practices. Infect Control Hosp Epidemiol 2011; 32: 1187-1193.

[31] de Jong B et al. Pre-post evaluation of effects of a titanium dioxide coating on environmental contamination of an intensive care unit: the TITANIC study. J Hosp Infect 2017 (accepted manuscript).

[32] Sunada K, Watanabe T, Hashimoto K. Studies on photokilling of bacteria on $\mathrm{TiO}_{2}$ thin film. J Photochem Photobiol A 2003; 156: 227-233.

[33] Dunlop PSM, Sheeran CP, Byrne JA, McMahon MAS, Boyle MA, McGuigan KG. Inactivation of clinically relevant pathogens by photocatalytic coatings. J Photochem Photobiol A 2010; 216: 303-310.

[34] Ojajärvi J, Mäkelä P, Rantasalo I. Failure of hand disinfection with frequent hand washing: a need for prolonged field studies. J Hyg Camb 1977; 79:107-119.

[35] Larson E. Skin hygiene and infection prevention: More of the same or different approaches? Clin Infect Dis 1999; 29:1287-1294.

[36] Wang Y-L, Chen W-C, Chen Y-Y et al. Bacterial contamination on surfaces of public areas in hospitals. J Hosp Infect 2010;74:195-196. 
[37] Williams GJ, Denyer SP, Hosein IK, Hill DW, Maillard J-Y. Limitations of the efficacy of surface disinfection in the healthcare setting. Infect Control Hosp Epidemiol 2009; 30: 570573.

[38] Stevens N, Priest Cl, Sedev R, Ralston J. Wettability of photoresponsive titanium dioxide surfaces. Langmuir 2003; 19:3272-3275. 
Table 1: Classification of aerobic colony counts (ACCs).

\begin{tabular}{|l|l|l|l|}
\hline $\mathrm{cfu} / \mathrm{cm}^{2}$ & Name & Numerical descriptor & Binary score $^{a}$ \\
\hline 0 & No growth & 1 & Pass $=1$ \\
\hline$<2.5$ & Very slight growth & 2 & Pass $=1$ \\
\hline $2.5-12$ & Light growth & 3 & Fail $=0$ \\
\hline $12-40$ & Moderate growth & 4 & Fail $=0$ \\
\hline$>40$ & Heavy growth & 5 & Fail $=0$ \\
\hline${ }^{a}$ According to Dancer (2008). ${ }^{26}$ & & \\
\hline
\end{tabular}


Table 2: Factors (variables) found to influence the probability $p$ of failing the test, estimated using binary logistic regression, adopting (fail v. pass) as the dichotomous response variable: Estimated parameters $B_{i}$ for the logit model $\left[\log [p /(1-p)]=\right.$ Constant $\left.+B_{i}\right]$, where the subscript $i=1$ refers to the untreated sites and $i=2$ to the treated ones. ${ }^{e}$

\begin{tabular}{|l|r|c|c|c|c|}
\hline & \multirow{2}{*}{$\begin{array}{c}B^{a} \\
(\mathrm{SE})\end{array}$} & $P^{b}$ & \multirow{2}{*}{$\mathrm{OR}^{c}$} & \multicolumn{2}{|c|}{$95 \% \mathrm{Cl}^{d}$} \\
\cline { 5 - 7 } & 0.000 & & 1.00 & & \\
\hline Control ward & $\begin{array}{r}-0.007 \\
(0.670)\end{array}$ & 0.991 & 0.993 & 0.267 & 3.690 \\
\hline Treated ward & $\begin{array}{r}0.026 \\
(0.009)\end{array}$ & 0.003 & 1.026 & 1.009 & 1.043 \\
\hline $\begin{array}{l}\text { Days into the evaluation } \\
\text { (for the control ward) }\end{array}$ & $\begin{array}{r}-0.051 \\
(0.014)\end{array}$ & 0.000 & 0.950 & 0.925 & 0.977 \\
\hline Treated ward-by-days & $\begin{array}{r}0.076 \\
(0.034)\end{array}$ & 0.026 & 1.079 & 1.009 & 1.154 \\
\hline Bed occupancy (\%) & $\begin{array}{r}-7.866 \\
(3.099)\end{array}$ & 0.011 & 0.000 & & \\
\hline Constant & & & & & \\
\hline
\end{tabular}

${ }^{a}$ Slope parameter of the continuous covariate (days), with its standard error in parentheses.

${ }^{b}$ Measure of significance.

${ }^{c}$ Odds ratio, equal to $\exp (B)$.

${ }^{d}$ Confidence intervals for $\exp (B)$.

${ }^{e}$ The control ward was estimated as the baseline constant parameter (at day zero) and the treated ward effect was estimated as a deviation from this constant parameter. The number of days from day zero and bed occupancy were introduced as continuous covariates. 
Table 3: Success probabilities $p$ for the (lack of) aerobic growth at the various sites.

\begin{tabular}{|c|c|c|c|c|c|c|c|}
\hline \multirow[t]{2}{*}{ Site } & \multicolumn{2}{|l|}{$p$} & \multicolumn{2}{|c|}{$\begin{array}{l}\text { Number of } \\
\text { observations }\end{array}$} & \multicolumn{2}{|l|}{$s^{a}$} & \multirow[t]{2}{*}{$\begin{array}{l}\left|p_{\text {treated }}-p_{\text {control }}\right| / \mid \\
\left(s_{\text {treated }}+s_{\text {control }}\right)^{b}\end{array}$} \\
\hline & Treated & Control & Treated & Control & Treated & Control & \\
\hline $\begin{array}{l}\text { Left side } \\
\text { bedrail }\end{array}$ & 0.66 & 0.51 & 98 & 102 & 0.05 & 0.05 & 1.5 \\
\hline $\begin{array}{l}\text { Right side } \\
\text { bedrail }\end{array}$ & 0.82 & 0.44 & 98 & 102 & 0.04 & 0.05 & 4.2 \\
\hline $\begin{array}{l}\text { Control } \\
\text { panel }\end{array}$ & 0.80 & 0.73 & 99 & 97 & 0.04 & 0.05 & 0.8 \\
\hline $\begin{array}{l}\text { Bedside } \\
\text { table }\end{array}$ & 0.86 & 0.75 & 99 & 95 & 0.03 & 0.04 & 1.6 \\
\hline $\begin{array}{l}\text { Bedside } \\
\text { locker }\end{array}$ & 0.95 & 0.79 & 87 & 102 & 0.02 & 0.04 & 2.7 \\
\hline $\begin{array}{l}\text { Bed } \\
\text { footboard }\end{array}$ & 0.51 & 0.48 & 87 & 91 & 0.05 & 0.05 & 0.3 \\
\hline All sites & 0.77 & 0.61 & 568 & 577 & 0.018 & 0.020 & 4.2 \\
\hline
\end{tabular}

\footnotetext{
${ }^{a}$ The span $s$ is the square root of the observed formation, which is a measure of the uncertainty of $p .^{28}$

${ }^{b}$ The difference between the probabilities divided by the sum of the spans is an index of the significance of the result: the greater the index, the greater the significance.
} 
Table 4: Environmental audits for housekeeping compliance with cleaning. ${ }^{a}$

\begin{tabular}{|c|c|c|c|c|}
\hline \multirow[t]{2}{*}{ Month } & \multicolumn{2}{|c|}{$\begin{array}{l}\text { Monthly "Health Assure" } \\
\text { environmental audit scores }\end{array}$} & \multicolumn{2}{|c|}{$\begin{array}{l}\text { Monthly "Credits for Cleaning” } \\
\text { (C4C) environmental audit scores }\end{array}$} \\
\hline & Treated ward & Control & Treated ward & Control \\
\hline September & $98.2 \%$ & $93.6 \%$ & $99.5 \%^{b}$ & $98.1 \%^{b}$ \\
\hline October & $99.1 \%$ & $84.0 \%$ & $98.4 \%^{c}$ & $99.4 \%^{c}$ \\
\hline November & $98.2 \%$ & $87.0 \%$ & $99.0 \%{ }^{d}$ & $97.7 \%^{d}$ \\
\hline December & $90.0 \%$ & $84.6 \%$ & $98.8 \%^{e}$ & $99.6 \%^{e}$ \\
\hline
\end{tabular}

a The audits do not directly observe the staff actually cleaning but inspect the whole ward environment, including high-touch surfaces.

${ }^{b}$ Week commencing 19 September.

${ }^{c}$ Week commencing 24 October.

${ }^{d}$ Week commencing 28 November.

${ }^{e}$ Week commencing 9 January. 


\section{FIGURE LEGEND}

Figure 1. Actual data (open circles) and predicted values (open triangles) for the control sites and treated sites (data: closed blue-grey circles; predicted values: closed triangles) for the duration of the evaluation. The vertical axis is microbial growth according to the 5-point scale (Table 1).

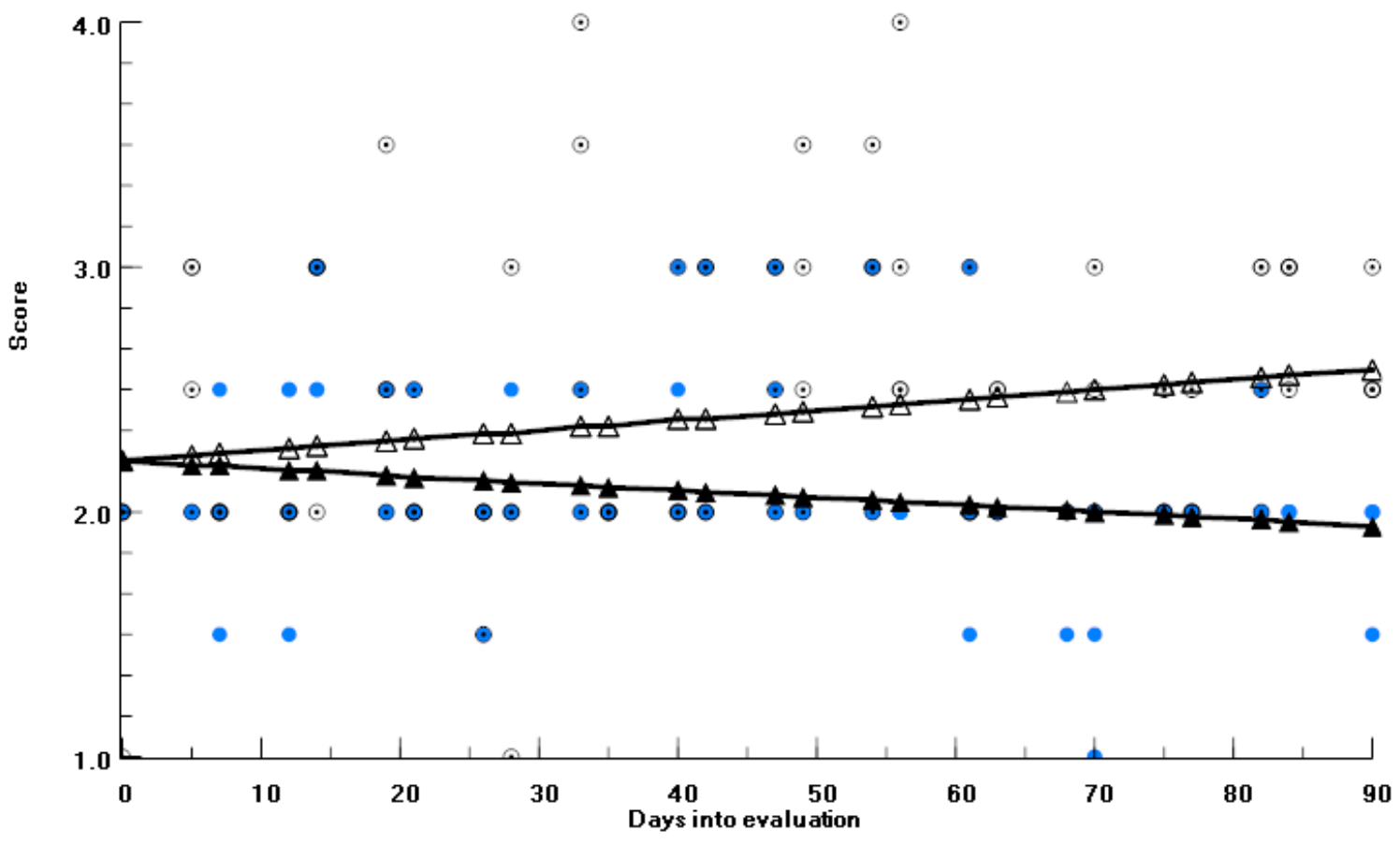

